\begin{tabular}{|c|c|c|c|c|}
\hline Phối hợp & $4(2.1 \%)$ & $5.25 \pm 3.95$ & $14.0 \pm 5.0$ & $\mathrm{p}<0.01$ \\
\hline Video phóng đại & $17(9.0 \%)$ & $9.2 \pm 6.3$ & $16.9 \pm 8.4$ & $\mathrm{p}<0.001$ \\
\hline
\end{tabular}

So sánh khoảng cách đọc sau trợ thị thây rằng ở người khiếm thị tuổi trưởng thành khoảng cách đọc cải thiện hơn so với trẻ khiếm thị, điều này do môt số người khiếm thi trên 40 tuổi ngoài khiếm thị họ còn kèm theo tật lão thị, mắt giảm khả năng điều tiết khi nhìn gần. Mặc dù với kính lúp cầm tay, khoảng cách đọc sau trợ thị là 12.8 $\pm 5.3 \mathrm{~cm}$ nhưng người khiếm thị ở tuổi này vẫn ưa thích dùng hơn kính lúp cầm tay hơn.

\section{KẾT LUẬN}

Sau trợ thị, thị lực nhìn gần và khoảng cách đọc của người khiếm thị cải thiện rõ rệt. Ở trẻ khiếm thị, trợ thị gần bằng kính gọng phóng đại được sử dụng nhiều nhất còn ở người khiếm thị trưởng thành kính lúp cầm tay được sử dụng nhiều nhất.

\section{TÀI LIÊU THAM KHẢO}

1. Adams, O. F., Rehabilitation services, Low vision manual. 2007, $291-307$.
2. Cho J., Lee S., Low vision devices for children, Community eye health journal. 2007, Vol 20(62): 28-29.

3. Margrain, T. H., Helping blind and partially sighted people to read: the effectiveness of low vision aids, BJO. 2000, 84 (8), 919-21

4. N̦guyển Thị Thu Hiến, Nguyễn Xuân Hiệp. Ứng dụng phương pháp phục hồi chức năng thị giác trển những người khiếm thị trưởng thành. Tạp chí Y học Việt nam. 2014; 417: 85-88.

5. Nguyển Vắn Lân, Nghiên cứu các phương pháp đánh giá và hỗ trợ bệnh nhân khiếm thị, Luân văn tốt nghiệp bác sỹ chưyên khoa cấp II. Trướng Đại học Y Hà nội. 2005.

6. Omar R., Mohammed Z., Kinght V.F., Profile of low vision children in the special education school in Malaysia, Original article. 2009, Vol64(4):289-293.

7. Sapkota K, Kim DH. Causes of low vision and major low-vision devices prescribed in the lowvision clinic of Nepal Eye Hospital, Nepal. Anim Cells Syst (Seoul). 2017; 21(3):147-151.

8. Tôn Thị Kim Thanh, Nguyê̂n Thị Thu Hiên. Nghiên cứu ứng dụng một sô dụng cụ trợ thị trên trẻ khiếm thị. Tạp chí nhãn khoa Việt nam. 2007; 9:45-54.

\title{
NGHIÊN CỨU TÌNH TRANG THỪA CÂN BÉO PHÌ VÀ MỐI LIÊN QUAN ĐẾN ĐÁI THÁO ĐƯỜNG SAU GHÉP THẬN
}

\section{TÓM TẮT}

Mục tiêu: Nghiên cứu tỉ lệ béo phì và mối liên quan đến đái tháo đường trên đối tượng 3 tháng sau ghép thận. Đối tượng và phương pháp nghiên cứu: Gồm 508 bệnh nhân có thời gian sau ghép thận $\geq 3$ tháng được theo dõi và điều tri sau ghép tai BV Việt Đức, từ 09/2017 đến 04/2018. Tất cả các bệnh nhân đều tự nguyên tham gia nghiên cứu. Bênh nhân được thăm khám lâm sàng, đo chiều cao cân nặng, được lấy máu vào buổi sáng trước khi ăn và uống thuốc ức chế miễn dịch. Thực hiện nghiệm pháp dung nap đường (OGTT) khi có chỉ đinhn. Tiến hành chẩn đoán, thừa cân béo phì, tiền đái tháo đường và đái tháo đường sau ghép thân theo tiêu chuẩn. Kết quả: Nhóm thửa cân, béo phì chiếm 30,12\% số bệnh nhân nghiên cứu. Tỷ lệ bệnh nhân được chẩn đoán NODAT có thừa cân béo phì là cao hơn có ý nghĩa thống kê so với những bệnh nhân không thừa cân béo phì, $\mathrm{p}=$ 0,003 . Nguy cơ phát triển NODAT trên những bệnh

${ }^{1}$ Bệnh viện Quân y 103

${ }^{2}$ Hoc viên Quân y

Chịu trách nhiệm chính: Đặng Thành Chung

Email: dangthanhchung@vmmu.edu.vn

Ngày nhận bài: 2.01.2021

Ngày phản biên khoa hoc: 25.2.2021

Ngày duyệt bài: 10.3.2021

\section{Nguyễn Đức Thuận ${ }^{1}$, Đặng Thành Chung²}

nhân thừa cân béo phì cao gấp 2,13 (95\%: 1,29-3,53) so những bệnh nhân không thửa cân béo phì. Kết luân: Nghiên cứu này cho thây tỉ lệ và nguy cơ mắc NODAT cao hơn ở những bệnh nhân thừa cân béo phì, vì thế để tránh thất bại sau ghép và các biến chứng quan, có vẻ hợp lý khi nhấn mạnh rằng những người được ghép tạng phải duy trì cân nặng bình thường.

Tư khóa: thừa cân, béo phì, đái tháo đường sau ghép thận

\section{SUMMARY \\ ASSOCIATIONS BETWEEN OVERWEIGHT, OBESITY, AND NEW-ONSET DIABETES AFTER RENAL TRANSPLANTATION}

Objectives: To study the ratio of overweight and obesity and the relationship with new-onset diabetes after three months of renal transplantation. Subjects and methods: ncluding 508 patients with kidney post-transplant more than three months who are followed up and treated at Viet Duc University Hospital from September 2017 to April 2018. All patients volunteered to participate in the study. Clinically examined, measured the height and weight of participants. Collect blood samples of recipients in the morning before eating and taking immunosuppressants. Carry out an oral glucose tolerance test (OGTT) when indicated. Diagnosis of overweight, obesity, pre-diabetes, and diabetes 
mellitus after kidney transplantation according to standards. Results: The overweight and obese group accounted for $30.12 \%$ of the study patients. The proportion of patients diagnosed with NODAT who were overweight and obese was statistically significantly higher than those who were not overweight and obese, $p=0.003$. The risk of developing NODAT in overweight and obese patients is 2.13 (95\%: 1.29-3.53) higher than in obese nonoverweight and obese patients. Conclusion: This study shows that the incidence and risk of NODAT is more heightened in overweight and obese patients, so to avoid post-transplant failure and related complications, it seems reasonable to emphasize that those who are renal transplants should maintain an average weight.

Key words; overweight, obesity, new-onset diabetes after transplantation.

\section{I. ĐĂT VẤN ĐỀ}

Đái tháo đường mới mắc sau ghép thận (New-onset diabetes after transplantation NODAT), là một trong những biến chứng chính sau khi cấy ghép tạng đặc [1]. Tỷ lệ mắc bệnh đái tháo đường trong nằm đầu tiên sau ghép thận cao hơn từ 5 đến 6 lần so với những bệnh nhân chờ ghép [2]. Biến chứng này được xem như nguyên nhân dẫn đến thất bại ghép và thúc đẩy bệnh tim mạch, một trong những nguyên nhân chính gây tử vong ở người được ghép tạng [3]. Có nhiều yếu tố nguy cơ được biết có liên quan đến NODAT, trong đó béo phì là một yếu tố nguy cơ phù hợp cho phát triển NODAT và trên thực thế dữ liệu từ "Hệ thống dữ liệu về thân Hoa Kỳ" cho thây béo phì có nguy cơ đối với NODAT là 1.73\% [4]. Tương tự như béo phì, thừa cân cũng là một yếu tố nguy cơ của NODAT [5]. Tuy nhiên, cũng cần phải xem xét ở khía canh khác là mặc dù nhiều bệnh nhân tăng cân đáng kể trong năm đâu tiên sau ghép, tỷ lệ NODAT không tương quan với trọng lượng tăng lên [5]. Cơ chế của thừa cân hoặc béo phì với NODAT cho đến nay vẫn chưa được hiểu rõ, mặc dù chúng ta đều biết răng bản thân béo phì có liên quan đến sự kháng insulin ở ngoại vi, một yếu tố nguy cơ có thể gây ra đái tháo đường tuýp 2. Hơn nữa, mô mõ có liên quan đến sự bài tiết các adipokine có thể đóng vai trò tác động vào cơ chế gây NODAT. Đã có nghiên cứu chỉ ra rằng cứ giảm $1 \mu \mathrm{g} / \mathrm{ml}$ của adiponectin trong huyết thanh làm tăng nguy cơ phát triển NODAT lên $13 \%$ [6]. Béo phì còn liên quan đến tăng các marker viêm trong huyết tương, là những chất gây ra kháng insulin. Theo báo cáo của Ibernon và cộng sự, việc giảm thấp manose gắn của lectin trong huyết thanh (một phân tử miễn dịch bẩm sinh sản xuất tại gan) có liên quan đến kháng insulin và do đó làm tăng nguy cơ NODAT [7].

Việc tăng khả năng sống sót của bệnh nhân ghép thận đòi hỏi phải được quan tâm đúng mức vì biến chứng của có thể cản trở thành công ghép và chất lượng cuộc sống của bệnh nhân. Chúng tôi tiến hành nghiên cứu này nhằm mục đích đánh giá tình trạng thừa cân béo phì và mối liên quan đến NODAT ở bệnh nhân sau ghép thận.

\section{II. ĐỐI TƯỢNG VÀ PHƯƠNG PHÁP NGHIÊN CỨU}

2.1 Đối tượng nghiên cứu: 508 bệnh nhân có thời gian sau ghép thận $\geq 3$ tháng được theo dõi và điều trị sau ghép tại $B V$ Việt Đức. Thời gian nghiên cứu từ 09/2017 đến 04/2018. Tất cả các bệnh nhân đều tự nguyện tham gia nghiên cứu.

2.2 Phương pháp nghiên cứu: Bệnh nhân được thăm khám lâm sàng, đo chiều cao cân năng tại thời điểm nghiên cứu. Bệnh nhân được lấy máu vào buổi sáng trước khi ăn và uống thuốc ức chế miễn dịch.

Tiêu chuẩn chẩn đoán thừa cân, béo phì: Tính chỉ số khối cơ thể (BMI- Body Mass Index) theo công thức của WHO: BMI= Trọng lượng cơ thể $(\mathrm{kg}) /$ (chiều cao tính bằng mét) Phân loại BMI cho người châu Á (The New BMI Criteria For Asians) [8]. Căn cứ vào BMI, chia ra: Gầy : < 18; Bình thường: 18.5 - 22.9; Tiên béo phì: 23 24.9; Béo phì: > 25.

Tiêu chuẩn chẩn đoán đái tháo đường sau ghép tạng: dựa trên tiêu chuẩn của Hiệp hội Đái tháo đường Hoa Kỳ (ADA - American Diabetes Association) đối với đái tháo đường tuýp 2 [9], như sau: Glucose huyết tương lúc đói (nhịn ăn trước thời điểm xét nghiệm ít nhất 8 tiếng) $\geq 7,0$ $\mathrm{mmol} / \mathrm{L}(126 \mathrm{mg} / \mathrm{dL}) /$ hoặc Glucose huyết tương trong 2 giờ sau Nghiệm pháp gây tăng đường huyết theo đường uống (OGTT - Oral glucose tolerance test) $\geq 11.1 \mathrm{mmol} / \mathrm{L}(200 \mathrm{mg} / \mathrm{dL}) /$ hoăc Glucose huyết tương bình thường $\geq 11.1 \mathrm{mmol} / \mathrm{L}$ (200mg/dL), ở 3 lần đo khác nhau.

Tiêu chuẩn chẩn đoán tiền đái tháo đường: Glucose máu lúc đói $5,6-6,9 \mathrm{mmo} 1 / \mathrm{l}$ và glucose máu giờ thứ 2 của nghiệm pháp dung nạp glucose đường uống 7,8 - $11 \mathrm{mmo1} / \mathrm{l}$. Glucose lúc đói $5,6-6,9 \mathrm{mmo1} / \mathrm{l}$ và glucose máu giờ thứ 2 của nghiệm pháp dung nạp glucose đường uống $<7,8 \mathrm{mmo1} / \mathrm{l}$. Glucose lúc đói $<5,6 \mathrm{mmo} 1 / \mathrm{l}$ và glucose máu giờ thứ 2 của nghiệm pháp dung nạp glucose đường uống 7,8 - 11mmo1/l.

Sau khi các thông tin và số liệu đã được thu thập đầy đủ tiến hành phân tích trình bày dưới dạng trung bình, độ lệch chuẩn, tần suất và tỷ lệ phần trăm. So sánh trung bình giữa các biến 
phân nhóm và biến nhị phân. Tính chỉ số nguy cơ OR (Odds Ratio): bảng tiếp liên $2 \times 2$. Tính hệ số tương quan r. Số liệu được xử lý theo các thuật toán thông kê y học sử dụng phần mềm Stata 12.0 với $p<0,05$ sẽ được chấp nhận là sự khác biệt có ý nghĩa thống kê.

\section{KẾT QUẢ NGHIÊN CỨU}

Bảng 1. Phân bố đôi tượng nghiên cứu theo BMI.

\begin{tabular}{|c|c|c|}
\hline BMI & Số lượng (n) & Tỷ lệ (\%) \\
\hline$<18,5$ & 76 & 14,96 \\
\hline
\end{tabular}

\begin{tabular}{|c|c|c|}
\hline $18,5-22,9$ & 279 & 54,92 \\
\hline$\geq 23$ & 153 & 30,12 \\
\hline Tống số & $\mathbf{5 0 8}$ & $\mathbf{1 0 0}$ \\
\hline \multicolumn{2}{|c|}{ Trung bình (X \pm SD): $21,60 \pm 3,15$} \\
\hline Min-Max & \multicolumn{2}{|c|}{$14,15-38,16$} \\
\hline
\end{tabular}

Nhận xét: Trong 508 đối tượng nghiên cứu, nhóm bệnh nhân có BMI trung bình $(18,5-22,9)$ chiếm tî lệ cao nhất với 54,92\%. BMI trung bình của cả quần thể nghiên cứu là 21,60 với độ lệch chuẩn 3,15. Nhóm thừa cân có BMI trên 23 chiếm 30,12\% số bệnh nhân nghiên cứu.

Bảng 2. Liên quan giứa NODAT với BMI

\begin{tabular}{|c|c|c|c|c|}
\hline Nhóm BMI & $<\mathbf{1 8 , 5}$ & $\mathbf{1 8 , 5 - 2 2 , 9}$ & $\mathbf{2 ~ 2 3}$ & P \\
\hline Glucose bình thường $\mathrm{n}(\%)$ & $67(88,16)$ & $224(80,29)$ & $105(68,63)$ & \multirow{2}{*}{0.005} \\
\hline NODAT $\mathrm{n}(\%)$ & $5(6,58)$ & $37(13,26)$ & $36(23,53)$ & \\
\hline Tiền ĐTĐ $\mathrm{n}(\%)$ & $4(5,26)$ & $18(6,45)$ & $12(7,84)$ & \\
\hline Tống số $\mathrm{n}(\%)$ & $76(100 \%)$ & $279(100)$ & $153(100)$ & \\
\hline
\end{tabular}

Nhận xét: Trong nhóm được bệnh nhân có BMI > 23, có 36 bệnh nhân được chẩn đoán NODAT, chiếm 23,53\%. Hai nhóm còn lại có chiếm tỉ lệ tương đương nhau. Tỷ lệ phẩn bố theo BMI trong chẩn đoán NODAT là khác biệt có ý nghĩa thống kê với độ tin cậy $95 \% \mathrm{p}=0,005$.

Bảng 3: Liên quan NODAT và tiền ĐTĐ với thừa cân béo phi

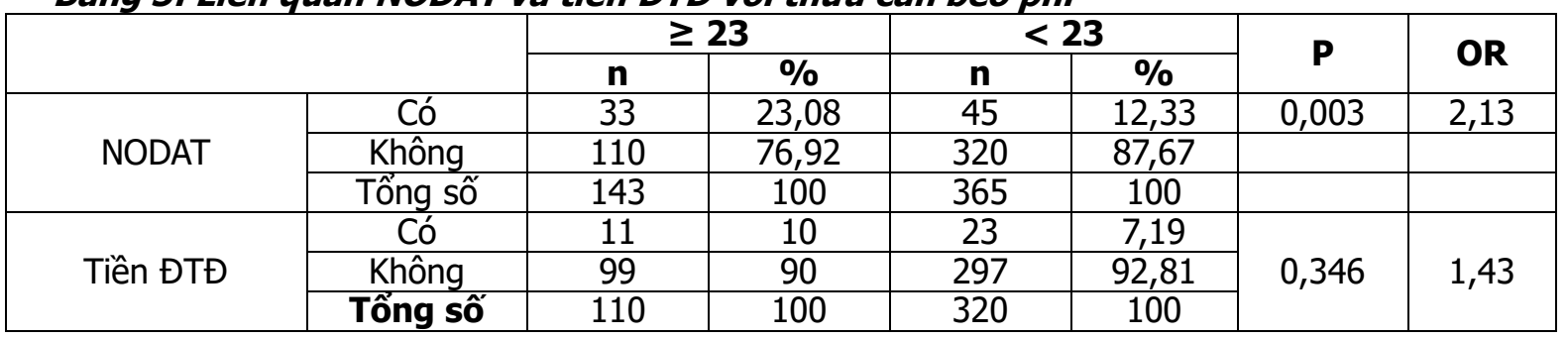

Nhận xét: Tỷ lệ bệnh nhân được chẩn đoán NODAT của phân loại thừa cân béo phì là khác biệt có ý nghĩa thống kê với độ tin cậy đạt $95 \%$ với $p=0,003$. Nguy cơ NODAT trên những bệnh nhân thừa cân béo phì cao gấp 2,13 lần trên những bệnh nhân không thừa cân béo phì khoảng tin cậy $\mathrm{OR}=2,13$ (95\%: 1,29-3,53).

Tỷ lệ bệnh nhân tiền ĐTĐ của phân loại thừa cân béo phì khác biệt không có ý nghĩa thống kê với độ tin cậy đạt $95 \%$ với $p=0,085>0,05$

\section{BÀN LUÂ̂N}

Béo phì là một trong những yếu tố nguy cơ quan trọng trong phát triển đái tháo đường type 2 trong cộng đồng. Tuy nhiên đây cũng là một trong nhứng yếu tố nguy cơ quan trọng liền quan đến phát triển NODAT trong hầu hết các nghiên cứu. Trong đối tượng nghiên cứu của chúng tôi người có $B M I \geq 23$ chiếm $30,12 \%$ đây là những đối tượng xếp vào nhóm thừa cân béo phì. Ở đối tượng NODAT, BMI trong khoảng 18,5 $-22,9$ và $\geq 23$ chiến phấn lớn với tî lệ lần lượt là $47,44 \%$ và $46,15 \%$, với sự khác biệt với nhóm có $\mathrm{BMI}<18,5$ có ý nghĩa thống kê $\mathrm{p}=0,001$. Như vậy hầu hết đối tượng bị NODAT là thừa cân hoặc béo phì. Chúng tôi cũng tiến hành phân tích liên quan giữa béo phì và NODAT, kết quả cho thây nguy cơ NODAT trên những bệnh nhân thừa cân béo phì cao gấp 2,13 lần trên những bệnh nhân không thừa cân béo phì với $p=0,0025$. Trong nghiên cứu của Bonato và cộng sự cho thấy những đối tượng có phát triển đái tháo đường sau ghép thận và có rối loạn chuyển hóa đường hầu hết là người thừa cẩn béo phì. Kết quả của nghiên cứu cũng chỉ ra rằng, cân nặng là yếu tố quan trọng cho phát triển NODAT. Theo phân tích thổng kê từ hệ thống dữ liệu về thận của Mỹ cho thấy những người thừa cân béo phì có $B M I \geq 30$ là một trong những yếu tố nguy cơ quan trọng nhất cho phát triển NODAT (với nguy cơ tương đối là $1,73, p<0,0001)$. Mặc dù một số nghiên cứu chưa đưa ra bằng chứng thuyết phục về mối liên quan giữa thừa cân béo phì và sự phát triển của NODAT, tuy nhiên béo phì đã được chỉ ra có liên quan đến tình trạng kháng insuline ngoại vi và 
đã được biết là yếu tố nguy cơ phát triển đái tháo đường type 2. Tuy nhiên giả thuyết về sự phân bố mõ trong cơ thể được cho là đóng vai trò quan trọng. Trong một nghiên cứu trên đối tượng là những người khỏe manh cho thấy những người béo phì ở phần cao của cơ thể hay dạng béo phì kiểu nam giới có liên quan nhiều hơn đến tình trang kháng insuline và rối loạn chuyển hóa đường so với những đối tương béo phì ở phần thấp của cơ thể hay béo phì dạng nữ. Gần đây một số nghiên cứu đã cho thấy các adipokine (là các cytokine được tiết ra bởi mô mõ̃) có khả năng điều hòa quá trình chuyển hóa, phản ứng viêm và đặc biệt có vai trò quan trọng trong trong bệnh sinh của đái tháo đường type 2 do liên quan đến quá trình kháng insuline và giảm nhạy cảm của insuline ở mô đích. Cơ chế của béo phì và tình trạng kháng insuline liên quan đến NODAT vẫn chưa được rõ ràng.

\section{KẾT LUÂN}

Nghiên cứu này cho thấy nguy cơ mắc NODAT cao hơn ở những người thừa cân béo phì ở tất cả những người được ghép tạng. Các nghiên cứu tiền cứu và đa trung tâm có thể hữu ích để hiểu rõ hơn và ngăn ngừa NODAT.

\section{TÀI LIỆ THAM KHẢO}

1. $\mathbf{Y u}, \mathbf{H}$., et al., Risk factors for new-onset diabetes mellitus after living donor kidney transplantation in
Korea - a retrospective single center study. BMC nephrology, 2016. 17(1): p. 106-106.

2. Chakkera, H.A., Y. Kudva, and B. Kaplan, Calcineurin Inhibitors: Pharmacologic Mechanisms Impacting Both Insulin Resistance and Insulin Secretion Leading to Glucose Dysregulation and Diabetes Mellitus. Clin Pharmacol Ther, 2017. 101(1): p. 114-120.

3. Davidson, J., et al., New-onset diabetes after transplantation: 2003 International consensus guidelines. Proceedings of an international expert panel meeting. Barcelona, Spain, 19 February 2003. Transplantation, 2003. 75(10 Suppl): p. Ss3-24.

4. Kasiske, B.L., et al., Diabetes mellitus after kidney transplantation in the United States. Am J Transplant, 2003. 3(2): p. 178-85.

5. Rodrigo, E., et al., New-onset diabetes after kidney transplantation: risk factors. J Am Soc Nephrol, 2006. 17(12 Suppl 3): p. S291-5.

6. Bayes, B., et al., Obesity, adiponectin and inflammation as predictors of new-onset diabetes mellitus after kidney transplantation. Am J Transplant, 2007. 7(2): p. 416-22.

7. Ibernon, M., et al., Low serum mannose-binding lectin as a risk factor for new onset diabetes mellitus after renal transplantation. Transplantation, 2009. 88(2): p. 272-8.

8. Anuurad, E., et al., The New BMI Criteria for Asians by the Regional Office for the Western Pacific Region of WHO are Suitable for Screening of Overweight to Prevent Metabolic Syndrome in Elder Japanese Workers. Journal of Occupational Health, 2003. 45(6): p. 335-343.

9. Genuth, S., et al., Follow-up report on the diagnosis of diabetes mellitus. Diabetes Care, 2003. 26(11): p. 3160-7.

\section{NGHIÊN CỨU CÁC DIỄN BIẾN BẤT LỢI Ở BÊ̂NH NHÂN TẮC ĐộNG MẠCH NÃO ĐƯợC LẤY HUYẾT KHỐI Cơ HỌC Có ĐIỀU TRI BẮC CẦU}

\section{TÓM TẮT}

Mục tiêu nghiên cứu: Nghiên cứu các biến chứng do tái thông mạch mạch máu não bằng tiêu sợi huyết kết hợp lấy huyết khối cơ học. Đối tượng và phương pháp nghiên cứu: Các bệnh nhân đột quy. nhồi máu não mạch lớn trước 270 phút, có chỉ định đồng thời tiêu sợi huyết liêu $0.9 \mathrm{mg} / \mathrm{kg}$ và lấy huyết khối cơ học. Đánh giá các diễn biến bất lợi, đặc biệt chảy máu não sau tái tưới máu. Kết quả: Với 35 bênh nhân thu được, tỷ lệ tái thông mạch tốt (TICI $2 \mathrm{~b}-\mathrm{c}$ ) là $94 \%$, hôi phục tốt thời điểm 90 ngày là $62,9 \%$ (mRS $0-2$ ). Tỷ lệ xuất huyết chuyển dạng là $37,1 \%$ trong đó

${ }^{1}$ Trung tâm điện quang, Bệnh viện Bạch Mai

Chiu trách nhiệm chính: Trần Anh Tuấn ${ }^{1}$

Email: Bs.trananhtuan@yahoo.com.vn

Ngày nhận bài: 5.01.2021

Ngày phản biện khoa học: 26.2.2021

Ngày duyệt bài: 9.3.2021

\section{Trần Anh Tuấn ${ }^{1}$}

chủ yếu là xuất huyết chuyển dạng không triệu chứng $10 / 13$ bệnh nhân xuất huyết $(76,9 \%)$. Ngoài ra có thể gặp một số diễn biến bất lợi khác như viêm phổi $(5,8 \%)$, suy thân $(5,85)$, suy giảm thần kinh sớm $(8,6 \%)$. Kết luận: Xuất huyết chuyển dạng là biến chứng hay gặp sau điều trị tiêu sợi huyết kêtt hợp lấy huyết khối động mạch $(37,1 \%)$ nhưng kỹ thuật này vẫn là phương pháp hiệu quả trong điều trị đột quy não tắc mach lớn.

Tư khóa: Đột quy não, tiêu sợi huyết, lây huyết khối cơ học, xuất huyết chuyển dạng

\section{SUMMARY \\ EVALUATION THE COMPLICATIONS OF BRIDGING THERAPY IN ISCHEMIC STROKE PATIENTS}

Purpose: The aim of this study was to evaluate the complications associated with brain artery recanalization using combined intravenous thrombolysis and mechanical thrombectomy. 